\title{
PALABRAS DE ENRIQUE VEGA GÓMEZ EN EL DÉCIMO ANIVERSARIO DE LA REVISTA CUESTIONES CONSTITUCIONALES
}

Distinguidos integrantes del presidium.

Estimado señor ex gobernador, coordinador general del Consejo Consultivo del Bicentenario de la Independencia de México en la Entidad y presidente de la Fundación UAEMEX, maestro en derecho César Camacho Quiroz.

Respetable maestro en derecho Baruch Delgado Carbajal, magistrado presidente del Tribunal Superior de Justicia y del Consejo de la Judicatura del Estado de México.

Honorable doctor Héctor Fix-Fierro, director del Instituto de Investigaciones Jurídicas de la UNAM.

Distinguido doctor Edgar Corzo Sosa, director de Cuestiones Constitucionales, Revista Mexicana de Derecho Constitucional.

Muy distinguido auditorio que nos acompaña.

Medios de comunicación.

Con enorme satisfacción expreso a nombre del señor rector de esta máxima casa del saber, maestro en ciencias Eduardo Gasca Pliego, la cordial bienvenida a todos y cada uno de ustedes, con quienes compartiremos, con alto honor, el festejo del décimo aniversario del importante texto constitucional que hoy se presenta en este solemne e histórico recinto.

Sean todos muy bienvenidos.

Para mi, representa un enorme compromiso, pero a su vez un profundo placer, el estar hoy aquí, con distinguidos juristas y académicos, por invitación de un estimado y respetable amigo, el maestro César Camacho Quiroz, a quien manifiesto mi gratitud por esta deferencia inmerecida para expresar algunos comentarios sobre la revista Cuestiones Constitucionales, que desde hace 10 años publica el Instituto de Investigaciones Jurídicas de la UNAM, y reconocer la amplia trayectoria de su director incansable, el doctor Edgar Corzo Sosa. 
La indiscutible calidad de la revista ha permitido que en sus páginas, podamos encontrar lo más granado en la investigación jurídica, de grandes juristas de nuestro tiempo.

En el número 21 de la revista que hoy nos convoca, encontramos una sección de interesantes artículos; otra de comentarios jurisprudenciales y, una tercera, sobre comentarios legislativos.

En cuanto a la primera, destacamos el estudio de Jorge Carpizo sobre Transparencia, acceso a la información y la universidad pública autóno$m a$, que muestra el inescindible vínculo entre la autonomía de nuestras Universidades y el derecho a la información, donde el autor destaca que entre los derechos constitucionales no existen conflictos.

Leemos asimismo, los efectos de la acción de tutela más allá de los casos concretos. La protección de los derechos fundamentales en Colombia, en la que Natalia Bernal Cano expone sus ideas en torno a la protección constitucional de los derechos y la pertinencia de incorporar los procesos de revisión judicial con efectos generales en los casos concretos resueltos por la acción de tutela.

Otros temas de gran calado, bordan sobre la actualidad del Estado y la justicia constitucional. Tal es el caso del estudio que Julio Bustillos realiza sobre La realidad de la justicia constitucional local mexicana del siglo XXI (a través de sus resoluciones definitivas), o el de Sergio López-Ayllón y Florencio Valladares acerca de Las acciones de inconstitucionalidad en la Constitución mexicana: balance empírico de 12 años de ejercicio.

La Revista se nutre asimismo, de los estudios sobre temas que incluso traspasan el ámbito nacional, como el de Mario Melgar Adalid intitulado La Suprema Corte de Obama, o el de John Fernando Restrepo Tamayo, Tribunales constitucionales: dinamizadores en la construcción de la democracia contemporánea para John Rawls. Otro más, es el estudio de Julia Sánchez Sánchez sobre Efectos de las sentencias constitucionales en el derecho argentino. Asimismo, Francisco Zúñiga Urbina, analiza la Constitución y "cláusulas económicas y sociales". Como algunas notas acerca de la operatividad de las normas constitucionales.

Con esta riqueza temática, la revista Cuestiones Constitucionales se ha constituido como uno de los mejores espacios para el análisis y reflexión, incluso, en temas trascendentes, como el de Luis Efrén Ríos Vega, sobre El transfuguismo electoral. Un debate constitucional en México, o el de 
Rodrigo Gutiérrez Rivas que versa sobre Garantias de protección del derecho fundamental al agua en México: un panorama; encontrando otro estudio de gran impacto en el que Carlos Elizondo ayer-Sierra y Luis Manuel Pérez de Acha, plantean: ¿Un nuevo derecho o el debilitamiento del Estado? Garantía de audiencia previa en la expropiación.

De "Los comentarios jurisprudenciales", destaco que en "La crónica jurisprudencial de 2008" de Edgar Corzo Sosa, se manifiesta el esfuerzo del control constitucional del pleno de nuestro máximo tribunal, en donde los criterios refieren a los derechos humanos, al sistema integral de justicia para adolescentes, a la seguridad social, así como las preocupaciones sociales que demostró la Corte para proporcionar un entendimiento jurisprudencial del contenido de las reformas constitucionales.

Respecto a "La libertad religiosa ante la Suprema Corte de Justicia, comentario al amparo en revisión" que realiza Miguel Carbonel, se refiere a la inconstitucionalidad del bando municipal de esta ciudad de Toluca, que establecía una sanción para aquellas personas que "sin permiso peguen, cuelguen, distribuyan o pinten propaganda de carácter comercial o de cualquier otro tipo en edificios públicos, portales, postes de alumbrado público..." resolviendo la Corte la inconstitucionalidad por considerar que el Estado no puede someter las actividades expresivas o comunicativas de los particulares a las necesidades de solicitar previamente un permiso a la autoridad.

Tocante a "La importancia de la presidencia de Barack Obama para la Constitución de los Estados Unidos", por Geraldina González de la Vega, se destaca que la interpretación de la ley fundamental no puede estar en manos de los grupos, por ello al ser designado presidente Obama, tenía la responsabilidad de nombrar los jueces ya que esta, la Corte, es el último bastión de los partidos, subrayando que los jueces no deben obedecer a estos ni a ideologías y mucho menos a los otros dos poderes.

Que la justicia constitucional no debe favorecer causas, ni debe apoyar ideologías, su vocación es favorecer normas y principios de convivencia soberanas.

Por lo que hace a los comentarios contra "La impunidad: consideraciones sobre la prueba ilícita a partir del caso Lidia Cacho, en la Suprema Corte de Justicia de la Nación"; Francisco Ibarra Palafox sostiene que es necesario abrir el debate sobre la posibilidad de admitir pruebas ilícitas en casos especiales y necesarios, como este, cuando esto sea indispensa- 
ble para la protección de los derechos fundamentales o pueda vulnerar el derecho básico de allegarse de los medios pertinentes de prueba con sus limitantes.

En cuanto a los comentarios acerca de "La recepción jurisprudencial del principio de proporcionalidad en México" por parte de Rubén Sánchez Gil, señala, que este principio es una de las herramientas metodológicas más, importantes del constitucionalismo de nuestro tiempo. Que es de carácter estructural del ordenamiento jurídico como el de no contradicción y el de exclusión (lo que no esta prohibido, esta permitido).

Que los juzgadores deben actuar "proporcionalmente" para hallar el punto medio en el que consistirá la justicia del caso.

De los comentarios legislativos; me referiré únicamente al de "Las reformas a la ley de expropiación relacionada con la garantía de audiencia" por parte de Marat Paredes Montiel y José María Soberanes Díez, en donde se refiere, que la garantía de audiencia previa a través de un procedimiento administrativo breve pero suficiente, cumple con la garantía del debido proceso legal, donde se notifica a los afectados el inicio del procedimiento y se les permite argumentar, presentar pruebas, desahogarlas en una audiencia y formular alegatos, contemplando además el dictado de una resolución final respecto a la causa de utilidad pública, y la indemnización al titular del derecho expropiado.

Se distinguen en la obra, las reseñas bibliográficas de auténticos íconos del derecho; en primer lugar la de Gustavo Zagrebelsky: "Principios y votos. El Tribunal Constitucional y la política" por parte de Miguel Carbonel, donde resalta la experiencia práctica y bibliográfica de la actividad del eminente juez de la Corte Constitucional Italiana, uno de los teóricos mas influyentes del movimiento neoconstitucionalista, señalando que la constitución se sitúa (debe situarse) por encima de la batalla política cotidiana. No puede ser convertida en rehén de ningún partido político y de ningún programa de gobierno; los jueces constitucionales no deben estar atados a la opinión pública, porque a veces deben tomar decisiones impopulares. No deben ceder frente a ningún tipo de presión. Afirmando que los jueces constitucionales deben militar en el "partido de la constitución”, el cual se ubica más allá de los partidos políticos.

En la reseña bibliográfica de Pedro Salazar Ugarte y Rodrigo Gutiérrez Rivas en su obra "El derecho a la libertad de expresión frente al derecho a la no discriminación. Tensiones, relaciones e implicaciones" 
que realiza el doctor Jorge Carpizo, se afirma que es legitimo limitar las libertades como la de expresión, para no infringir o anular derechos y libertades de otros, debido a que los derechos y libertades son para todos y de todos, para y de cada ser humano. La idea de igualdad circunscribe a la propia libertad, por ello el derecho y sus operadores deben tratar "diferente a quien necesita la diferencia para ser iguales".

La reseña bibliográfica de Mauro Cappelletti en sus obras "La justicia constitucional" y "Dimensiones de la justicia en el mundo contemporáneo" por Eduardo Ferrer Mac-Gregor, realiza un estudio sistemático de la justicia constitucional a la luz del derecho comparado. Destaca de la obra "La justicia constitucional" el control judicial de la constitucionalidad de leyes, el juez constitucional, sus poderes y legitimidad democrática, así como la justicia constitucional supranacional. Respecto a la obra "Dimensiones de la justicia en el mundo contemporáneo". Aborda que toda ciencia debe ser "ciencia útil" y sensible a las necesidades de la sociedad. Ciencia de problemas prácticos y no de sistematizaciones conceptuales abstractas. Ciencia de resultados concretos y no de deducciones apriorísticas.

Respecto a la reseña bibliográfica de la Suprema Corte de Justicia de la Nación, "Semblanza, vida y obra de los ministros de la Suprema Corte de Justicia de la Nación. Gabino Fraga Magaña". Por parte del doctor Sergio García Ramírez, indica que en estas semblanzas no solo se suministra una útil noticia en torno a los juristas que se han desempeñado como ministros de la Corte, sino porque a través de esta información, se provee a los lectores datos relevantes del desarrollo de la justicia federal.

Señala como Gabino Fraga Magaña, jurista prestigiado, investigador y docente, ha dejado una huella profunda en nuestro desarrollo constitucional y revolucionario. Fraga tuvo una presencia en el derecho administrativo al que aportó una obra básica destinada a la docencia; Fraga constituye la frontera entre el estudio tradicional del derecho administrativo y la elaboración moderna de esta especialidad en México. Acreditando su calidad de hombre universal comprometido con la dignidad del ser humano.

Finalmente toco de la obra la reseña; "Estudios de la defensa de la Constitución en el ordenamiento mexicano" de Héctor Fix-Zamudio, realizada por Manuel Aragón Reyes y el director del libro que hoy se presenta Edgar Corzo Sosa, en un verdadero reconocimiento a la trayec- 
toria personal como investigador y universitario ejemplar de don Héctor Fix-Zamudio, sus obras han traspasado fronteras puesto que ha realizado excelentes estudios de carácter constitucional. Jurista completo: con la sabiduría que otorga el conocimiento teórico y la ponderación o la prudencia, que proporciona el conocimiento práctico.

Se destaca en esta obra, que solo es auténtica constitución aquella que establece los mecanismos que garanticen su vigencia esto es, su aplicación. Mecanismos como conjunto de garantías políticas y como sistema de control jurídico, de control jurisdiccional. Que la Constitución es así limitación de poder jurídicamente garantizada, con el objetivo de asegurar la libertad de los ciudadanos.

Distinguido auditorio; ante la riqueza de la obra sólo he tenido la intención de realizar fugaces comentarios de la misma, ante el temor de cometer el exabrupto de abusar del tiempo. Finalizo con algo que considero como deber de conciencia; el recomendar ampliamente no solo la delicia que causa leer sus páginas, sino obtener la obra, que fortalecerá indudablemente nuestro conocimiento científico, nuestro acervo bibliográfico y la cultura jurídica de quienes acudamos a su consulta.

Felicidades doctor Edgar Corzo Sosa. 